\title{
Structure Elucidation of a Cryptic Condensation Product from Diacetyl and Arylamine - Then and Now
}

\author{
Lukas Hintermann ab*
}

\begin{abstract}
Some 70 years ago, the reaction of diacetyl (1) and arylamines (2) in hot phosphoric acid was reported to give a new type of condensation products, but no structure was assigned to them. The case is presented to recapitulate the methods and rationales used in classical structure elucidation of organic molecules through reaction networks, before spectroscopic or crystallographic methods were generally available. The difficulties and limits of the classical approach are exemplified through this real-life problem, which could not be solved by the methodology of its time. A representative condensation product $4 \mathrm{a}$ has been resynthesized from 1 and $p$-toluidine (2a), and its structure elucidation by means of 2D NMR techniques is outlined.
\end{abstract}

Keywords: Heterocycles · History of chemistry · NMR spectroscopy · Structure elucidation · Synthetic methodology

\section{Introduction}

The condensation of diacetyl (1) with arylamines $\mathbf{2}$ provides diimines $\mathbf{3}$ in a seemingly trivial manner (Scheme 1a). Numerous examples have been reported over the years, spreading back to the first report in the late $19^{\text {th }}$ century. ${ }^{[1-6]}$ We have relied on this useful reaction for preparing diimines like $\mathbf{L 1},{ }^{[2]}$ which serves as steering ligand in a novel nickel-catalyzed zincation of aryl tosylates that provides synthetically useful arylzinc reagents from non-standard sources (Scheme 1b). ${ }^{[7]}$

A literature search highlighted a 'Swiss connection' to diimines 3, when it transpired that Erlenmeyer and coworkers at the University of Basel had prepared and investigated them for tuberculostatic effects in the 1940s. ${ }^{[6,8,9]}$ Their studies initially verified bacteriostatic action for aromatic amines $\mathbf{2}^{[10]}$ as well as for dicarbonyl compounds including 1 in 1945.[11] Concomitantly, the combined inhibitory action of $\mathbf{1}$ and 4-aminobenzoic acid ( $\mathbf{2 b}$ ) was shown to be higher than of the individual agents. ${ }^{[11]}$ This led to the hypothesis that a condensation product $\mathbf{3 b}$ might have formed in situ from $\mathbf{1}$ and $\mathbf{2 b}$, which acts as a superior antibiotic agent. A study of the bacteriostatic data of no less than 33 condensation products of dicarbonyl compounds and arylamines was promptly delivered. ${ }^{[12]}$ The inhibition results do not stand out; what rather draws the attention of the presentday reader is that the exact nature of the tested condensation products was somewhat concealed, insofar as detailed information on their structure was postponed to future reports! The following year (1946), a paper on the synthesis of several diimines 3 from diacetyl (1) and several arylamines (2) appeared, which clarified the structure of the regular condensation products from alcoholic solution (Scheme 1a). ${ }^{[6]}$ Another study, entitled 'Über Kondensationen von Diacetyl mit primären aromatischen Aminen unter Zusatz von konzentrierter Phosphorsäure I' (On the Condensation of Diacetyl with Primary Aromatic Amines with the Addition of Concentrated Phosporic Acid I) was published three years later. ${ }^{[13,14]}$ This work clarified that a different type of condensation products $\mathbf{4}$ are formed from $\mathbf{1}$ and $\mathbf{2}$ in acid, but no structure was assigned to them. Why was there such a reluctant release of information?

The $1946 \mathrm{PhD}$ thesis of the first author F. Christen provides some background: ${ }^{[15,16]}$ While condensation of $\mathbf{1}$ with arylamines 2 often gave the expected diimines 3 effortlessly (Scheme 1a), ${ }^{[6]}$ reactions with $p$-aminobenzoic acid (PABA; 2b) or its esters as amine components failed for no obvious reason. This was displeasing, considering the anticipated antibiotic action of this condensation product. When switching to $85 \%$ phosphoric acid as reaction medium, $\mathbf{1}$ and $\mathbf{2}$ still underwent condensation, this time also in case of $\mathbf{2 b}$ as substrate. However, the resulting condensation products $\mathbf{4}$ were found to be chemically different from diimines $\mathbf{3}$. In spite of extensive, careful analytical work, which took up the larger part of

a)

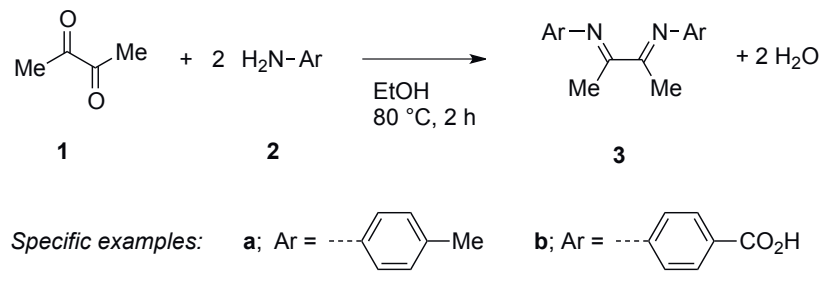

b) Diimine $\mathbf{L 1}$ as ligand in catalysis:
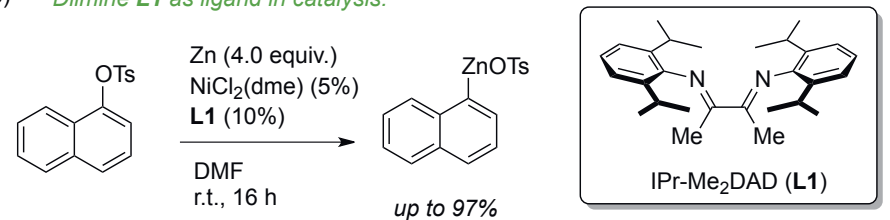

Scheme 1. a) Condensation of diacetyl (1) with arylamines (2) to form diimines (3). b) Application of a hindered diacetyl diimine (L1) in a nickelcatalyzed zincation reaction. 
a $\mathrm{PhD}$ thesis work, the structure elucidation of products $\mathbf{4}$ did not lead to a convincing result. ${ }^{[13,15]}$ What must have been frustrating at the time, presents us with a fascinating riddle today. In his book 'Classical Methods in Structure Elucidation of Natural Products', ,17] Hoffmann has recently unfolded the analytical basis and stringent logic behind structure elucidations with late 19th and early 20th century approaches, which rely on chemical reactivity networks. Here I wish to exemplarily highlight the classical structure elucidation approach by means of an ultimately failed example, namely that of the cryptic condensation product from arylamine and diacetyl in acid.

\section{Results and Discussion}

The condensation of diacetyl (1) with $p$-toluidine (2a) in hot $85 \%$ phosphoric acid is representative of the reactions described by Christen et al. in their 1949 paper. Table 1 presents the analytical evidence gathered for condensation product $\mathbf{4 a}$, which precipitates from the reaction mixture after dilution with water. ${ }^{[13,15]}$

The melting point (entry 1 ) of the product is different from that of diimine $3 \mathbf{a}\left(112^{\circ} \mathrm{C}\right)$, which indicated that a new compound had been formed, besides the differences in visual appearance and solubility. Elemental analysis $(\mathrm{C}, \mathrm{H}$, and $\mathrm{N}$; $\mathrm{O}$ by difference) re-

Table 1. Analytical evidence collected for condensation product 4 a by Christen et al $^{\text {a }}$

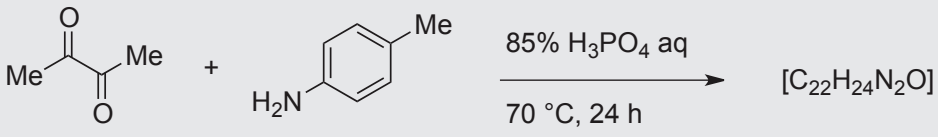

$2 a$

\section{Hindsight $^{\mathrm{c}}$}

Conclusion $^{\mathrm{b}}$

$4 a$

\begin{tabular}{|c|c|c|c|c|}
\hline Entry & Analytical Method & Result $^{b}$ & Conclusion $^{b}$ & Hindsight $^{\mathrm{c}}$ \\
\hline \multicolumn{5}{|c|}{ Physical properties and quantitative analysis } \\
\hline 1 & Melting point & $147.5^{\circ} \mathrm{C}$ (corr.) & $\mathbf{4 a} \neq \mathbf{3 a}$ & $\square\left(151-153{ }^{\circ} \mathrm{C}\right)$ \\
\hline 2 & Elemental analysis & $\mathrm{C}_{22} \mathrm{H}_{24} \mathrm{~N}_{2} \mathrm{O}$ & $2 \cdot \mathbf{1}+2 \cdot \mathbf{2} \mathbf{a}=\mathbf{4 a}+3 \mathrm{H}_{2} \mathrm{O}$ & $\square$ \\
\hline 3 & Cryoscopy & $\mathrm{M}_{\mathrm{r}} \approx 325$ & $\mathrm{C}_{22} \mathrm{H}_{24} \mathrm{~N}_{2} \mathrm{O}=332$ & $\nabla$ \\
\hline 4 & $\mathrm{H}_{2}$ or $\mathrm{Br}_{2}$ addition & 2 unsaturations & $\begin{array}{l}2 \mathrm{C}=\mathrm{C} \\
2 \text { new rings }\end{array}$ & $\begin{array}{l}\nabla / \widehat{\otimes}^{\mathrm{d}} \\
\text { 囚 }\end{array}$ \\
\hline 5 & Zerewitinoff & 2 equiv. of $\mathrm{CH}_{4}$ & $\begin{array}{l}\mathrm{RR}{ }^{\prime} \mathrm{NH} * \mathrm{e} \\
\mathrm{R}-\mathrm{N}=\mathrm{CR}^{1}-\mathrm{CHR}^{2} \mathrm{R}^{3}\end{array}$ & $\begin{array}{l}\square \\
\square\end{array}$ \\
\hline \multicolumn{5}{|c|}{ Reactivity (qualitative analysis) } \\
\hline 6 & $\begin{array}{l}\text { - } \mathrm{AcCl}-\mathrm{K}_{2} \mathrm{CO}_{3} \text {, or } \\
\text { - }{ }^{3,5}\left(\mathrm{O}_{2} \mathrm{~N}\right)_{2} \mathrm{C}_{6} \mathrm{H}_{3} \mathrm{COCl}\end{array}$ & $\begin{array}{l}\text { - monoacylation } \\
\text { - no diacylation }\end{array}$ & $\begin{array}{l}1 \mathrm{RR}^{\prime} \mathrm{NH} * \mathrm{e} \\
1 \text { tertiary nitrogen }\end{array}$ & $\begin{array}{l}\square \\
\square\end{array}$ \\
\hline 7 & $\mathrm{HCl}(g)$ & $\mathbf{4 a} \cdot \mathrm{HCl}$ salt & RR'NH *e & $\nabla / \otimes^{\mathrm{d}}$ \\
\hline 8 & $\mathbf{4 a} \cdot \mathrm{HCl}+\mathrm{NaNO}_{2}$ & nitroso-derivative $^{f}$ & RR'NH *e & $\nabla / \boldsymbol{x}^{\mathrm{d}, \mathrm{g}}$ \\
\hline 9 & $\mathbf{4 a}-\mathrm{HNO}_{2}+2-\mathrm{NapOH}$ & no azo coupling & absence of $\mathrm{ArNH}_{2} * \mathrm{e}$ & $\square$ \\
\hline 10 & $\mathrm{NaOH}$ aq or $\mathrm{HCl}$ aq & no $\mathbf{1}$ or $\mathbf{2 a}$ formed & absence of imine/amide & $\square$ \\
\hline 11 & $\begin{array}{l}\mathrm{NH}_{2} \mathrm{OH} \text {, semicarbazide, } \\
\text { or DNPH }\end{array}$ & no reaction & absence of ketone & 国 \\
\hline 12 & {$\left[2-\mathrm{NapN}_{2}\right] \mathrm{Cl}$} & no azo coupling & no activated $\mathrm{C}-\mathrm{H}$ & $\nabla$ \\
\hline 13 & $\mathrm{FeCl}_{3}-\mathrm{EtOH}$ & negative color test & no $\mathrm{ArOH}$ & $\square$ \\
\hline 14 & $\mathrm{O}_{2}(h \cdot v)$ & {$\left[\mathrm{M}+\mathrm{O}_{2}\right], \mathrm{C}_{22} \mathrm{H}_{24} \mathrm{~N}_{2} \mathrm{O}_{3}$} & $\mathrm{C}=\mathrm{C}$ & $\nabla / \widehat{\square}^{\mathrm{d}}$ \\
\hline 15 & $\mathrm{~K}_{2} \mathrm{Cr}_{2} \mathrm{O}_{7}-\mathrm{H}_{2} \mathrm{SO}_{4}$ & $\mathrm{PhCO}_{2} \mathrm{H}$ isolated $(90 \%)$ & $2 \times$ Tol-N intact & $\nabla^{\mathrm{g}}$ \\
\hline 16 & Spruce chip test ${ }^{\mathrm{h}}$ & brown color & furan or pyrrole & $\nabla / \boldsymbol{x}^{\mathrm{d}}$ \\
\hline 17 & Ehrlich reagent ${ }^{\mathrm{i}}$ & changing colors & possibly furan & $\boldsymbol{\otimes}^{\mathrm{d}, \mathrm{g}}$ \\
\hline 18 & $\mathrm{SbCl}_{3}-\mathrm{Ac}_{2} \mathrm{O}-\mathrm{CHCl}_{3}$ & changing colors & possibly furan & $\boldsymbol{\otimes}^{\mathrm{d}, \mathrm{g}}$ \\
\hline
\end{tabular}

a) Data compiled from refs. [13,15]. b) The results and conclusions are those obtained in 1946. c) 'Hindsight' assesses the 1946 findings and conclusions by current knowledge as being: $\square$ correct; $\mathbf{x}$ wrong or misleading. d) The experimental result was nominally correct, but inconclusive. e) Starred results must be combined to arrive at the conclusion. f) Derivative could not be analyzed (decomposition). g) Item was presented in the PhD thesis,[15] but not in the published paper.[13] h) A spruce chip (or: pine wood shaving; Ger. Fichtenspan), moistened with $\mathrm{HCl}$ aq, and exposed to analyte develops specific colors. i) $4-\left(\mathrm{Me}{ }_{2} \mathrm{~N}\right) \mathrm{C}_{6} \mathrm{H}_{4} \mathrm{CHO}-\mathrm{HCl}$ aq. $\mathrm{DNPH}=$ 2,4-dinitrophenylhydrazine; Nap = naphthyl. 
turned the formula $\mathrm{C}_{22} \mathrm{H}_{24} \mathrm{~N}_{2} \mathrm{O}$ (entry 1), for which the molecular mass was confirmed by cryoscopy in camphor (entry 3 ) and acidbase titration. On this basis, the condensation stoichiometry can be formulated as:[18]

$$
2 \mathrm{C}_{7} \mathrm{H}_{7} \mathrm{NH}_{2}+2 \mathrm{CH}_{3} \mathrm{COCOCH}_{3}=\mathrm{C}_{22} \mathrm{H}_{24} \mathrm{~N}_{2} \mathrm{O}+3 \mathrm{H}_{2} \mathrm{O}
$$

There are 12 DBE's (double bond- or ring-equivalents), ${ }^{[19]}$ of which eight can be ascribed to two assumedly still intact tolyl subunits. This leaves four DBE's for new structural elements. Based on bromine titration or hydrogen consumption, the presence of two double bonds - and accordingly two rings - was inferred (entry 4). The Zerewitinoff test ${ }^{[20]}$ (reaction with MeMgI, volumetric analysis of $\mathrm{CH}_{4}$ ) demonstrates the presence of two acidic hydrogens (entry 5), one of which is assigned to a secondary amine R'NHR, as supported by mono-acylation of $\mathbf{4 a}$ with acetyl chloride (entry $6),{ }^{[21]}$ the generation of a hydrochloride salt (entry 7), and generation of a nitroso-derivative (entry 8), although the latter was too labile for analysis. Primary amine was excluded by a negative azocoupling test (entry 9). Further functional group tests indicated the absence of imine or amide (entry 10), of aldehyde or ketone (inability to give oxime or hydrazones; entry 11), of activated C-H (entry 12), or of phenol (entry 13). Photo-oxygenation with uptake of $\mathrm{O}_{2}$ pointed to the presence of a $\mathrm{C}=\mathrm{C}$ double bond (entry 14). Chromic acid oxidation returned benzoic acid as only identified product, and in sufficient quantity to account for two tolyl subunits (entry $15)$. Some not overly specific color tests for heterocycles were performed (entries 16-18), namely a spruce chip (Ger. Fichtenspan) test (entry 16), ${ }^{[22]}$ and reaction with the Ehrlich (entry 17) or CarrPrice reagents (entry 18).[23,24] Finally, the substrate scope of the condensation reaction also revealed that benzoin $(\mathrm{PhCOCOPh})$ cannot replace $\mathbf{1}$ in the synthesis of $\mathbf{4}$, thus an enolizable $-\mathrm{COCH}_{3}$ group of $\mathbf{1}$ is necessarily involved in an aldol type condensation. At this point, some readers might want to try solving the structural puzzle, based on the collected evidence from 1946 alone.

In his $\mathrm{PhD}$ thesis, Christen presents the analysis along the following lines: ${ }^{[15]}$ First, it is critical to identify the oxygenated functional group, for which neither carbonyl, nor amide, nor phenol or alcohol seem to fit. That points to an ether, but leaves the identity of the second acidic proton in the Zerewitinoff test (see above) ambiguous; the presence of a weakly acidic, tautomerizable imine with a weakly basic tertiary nitrogen $\left(\mathrm{R}^{1} \mathrm{R}^{2} \mathrm{CH}-\mathrm{C}\left(\mathrm{R}^{3}\right)=\mathrm{NR}^{3}\right)$ was postulated. Ether formation must correspond to one of two expected ring closures, and therefore the compound should be an oxygen heterocycle. Two candidate structures were offered for $\mathbf{4 a}$ in the thesis, which are shown in Fig. 1. ${ }^{[15]}$
The structures reflect the necessity to accommodate the experimental findings in Table 1, even if they are intuitively not very satisfactory. Namely, if such compounds were present in a reaction medium of hot concentrated phosphoric acid, they would likely suffer elimination, tautomerization and dehydrogenation events. Considering a lack of positive evidence, it is not surprising that the candidate structures were left out of the published paper.[13]

I also have not arrived at a convincing structure proposal based on the evidence presented in Table 1. Thus, a condensation of $\mathbf{1}$ and $\mathbf{2 a}$ in phosphoric acid was repeated according to the procedure of Christen et al., and the resulting material was positively identified as $\mathbf{4 a}$ by melting point $\left(151-153{ }^{\circ} \mathrm{C}\right.$ vs 147.5 (corr.)), ${ }^{[25]}$ solubility, color and $\mathrm{CH}$-composition (derived from ${ }^{1} \mathrm{H}$ NMR integration and APT- ${ }^{13} \mathrm{C} \mathrm{NMR}^{[26]}$ peak data). The ${ }^{1} \mathrm{H}$ NMR spectrum of a $\mathrm{CDCl}_{3}$ solution revealed the presence of five isolated (singlet) methyl groups, two intact $p$-tolyl fragments, and a broadened $\mathrm{XH}$ signal at $\delta_{\mathrm{H}} 5.92$. The APT- ${ }^{13} \mathrm{C}$ NMR signals confirmed the first two items and additionally pointed to a conjugated ketone $\left(\delta_{C} 195.7\right)$, whose presence had gone unnoted in the earlier study, which immediately explains the severe problems facing the reactivity-based structure elucidation in this particular case. The spectral hints define six fragments, which include all atoms present in 1 (Fig. 2).

Considering reactivity-based plausibility and chemical shift data, we further assume that $\mathrm{XH}$ is a secondary Tol-NHR unit, and that a methyl ketone conjugated to a $\mathrm{C}=\mathrm{C}$ double bond will be present. Permutative combination of the above fragments in accord with their valency, while excluding strained 3- and 4-membered rings, generates a number of structures including $\mathbf{A}-\mathbf{J}$ (Fig. 2). Further exclusion of cumulenes (ketene imines; A, B) and alkynones $(\mathbf{C}, \mathbf{D}, \mathbf{E})$ - which would likely hydrolyze in hot aqueous<smiles>CC1=CC2Oc3cc(C)ccc3N=C2CC1(C)Nc1ccc(C)cc1</smiles><smiles>CC1=CC2Nc3ccc(C)cc3OC2(C)C/C1=N/c1ccc(C)cc1</smiles>

Fig. 1. Potential structures offered for 4 a in 1946. ${ }^{[15]}$

Fragments derived from NMR spectroscopy

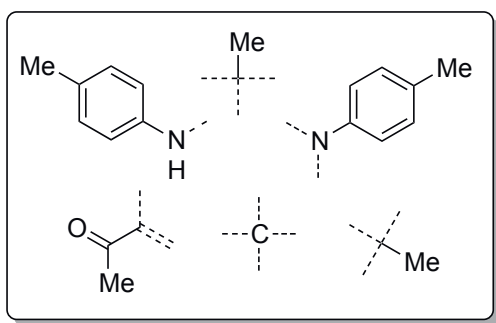

$$
\text { A }
$$<smiles>CNC(C(C)=O)=C(C)C(C)=C=[Nb]</smiles>

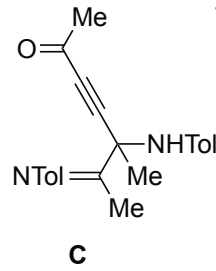<smiles>CN/C(C)=C(\C)[NH2+]C#CC(C)=O</smiles>

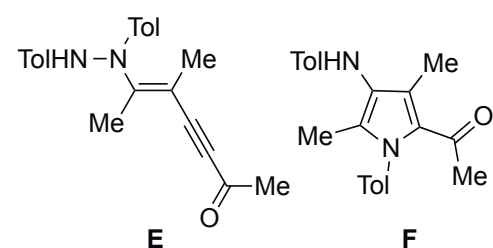<smiles>CCCCCNc1c(C(C)=O)c(C)n([AlH2])c1C</smiles>
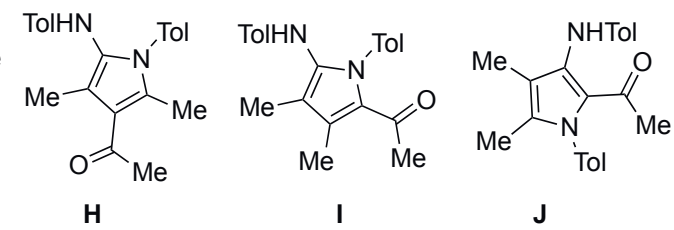

Fig. 2. Structure fragments of $4 \mathrm{a}$ defined by ${ }^{1} \mathrm{H}$ and ${ }^{13} \mathrm{C}$ APT-NMR peak data, with a selection of derived structures $\mathrm{A}-\mathrm{J}$ generated by permutative combination of fragments. 
phosphoric acid - narrows the choice to a set of regioisomeric pyrroles $\mathbf{F}-\mathbf{J}$, which are intuitively satisfactory, considering their aromatic stabilization.

At this point, 2D NMR techniques come into play to define the connectivity of the fragments through long-range correlations. ${ }^{[26}$ The ${ }^{1} \mathrm{H},{ }^{13} \mathrm{C}$-HMBC experiment ${ }^{[26]}$ failed to unequivocally attach the external substituents to the pyrrole core by lack of sufficient and suitable cross-peaks. This is not untypical for analytes that are 'meager in $\mathrm{H}$-atoms' (e.g., if the $\mathrm{H} /[\mathrm{C}+\mathrm{N}+\mathrm{O}+\mathrm{S}]$ ratio falls below 2 , or below 1 in smaller fragments; Crews rule $\left.{ }^{[27,28]}\right)$. Fortunately, the NOESY experiment ${ }^{[26]}$ permits to mutually position neighboring groups around the pyrrole core: ${ }^{6.58} \mathrm{Tol}-\mathrm{NH}^{[29]}$ correlates with ${ }^{1.80} \mathrm{Me}$, which also correlates with ${ }^{7.09} \mathrm{Tol}-\mathrm{N}$, and the latter further correlates with ${ }^{2.29} \mathrm{Me}$. This arrangement corresponds to structure $\mathbf{G}=\mathbf{4 a}$, as further confirmed by NOESY correlations from ${ }^{2.39} \mathrm{MeCO}$ to ${ }^{6.58} \mathrm{TolNH}$ (Fig. 3). ${ }^{[30]}$

The differentiation of the tolyl groups ${ }^{6.58} \mathrm{TolNH}$ vs ${ }^{7.09} \mathrm{TolN}$ relies either on a NOESY correlation from exchange-broadened ${ }^{5.9} \mathrm{NH}$ with ortho-CH of ${ }^{6.58} \mathrm{TolNH}$ (a correlation not seen by COSY), or more satisfactory long-range ${ }^{1} \mathrm{H},{ }^{15} \mathrm{~N}-\mathrm{HMBC}$, which also reveals ${ }^{15} \mathrm{~N}$ nitrogen shifts in accordance with the respective functionalities (Fig. 3).

It is the inability of $\mathbf{4 a}$ to provide an oxime, semicarbazone or hydrazone with hydroxylamine, semicarbazide or 2,4-dinitrophenylhydrazine, respectively, which ultimately led to the failure of the reactivity-based structure elucidation. But why are no such derivatives formed? Sterically hindered ketones sometimes provide imines with difficulty, and the acetyl group of pyrrole $\mathbf{4 a}$ is flanked on both sides. Furthermore, pyrrolyl ketones display low reactivity towards nucleophiles, ${ }^{[31]}$ although that does not usually prevent them from forming hydrazones. ${ }^{[32]}$

The matter was put to an experimental test: Samples of $\mathbf{4 a}$ and 2,4-dinitrophenylhydrazine (DNPH) were combined in an NMR tube and dissolved in $\mathrm{CDCl}_{3}$ with a little trifluoroacetic acid. The ${ }^{1} \mathrm{H}$ NMR spectrum of the sample showed signals for a new species, but retained the signals of unreacted DNPH. No sign of hydrazone formation was evident over the course of two days. Consequently, it must have been the interaction of $\mathbf{4 a}$ with the acid exclusively, which had generated the new species 5a. An NMR sample of pyrrole $4 \mathbf{a}$ and 3 equiv. of $\mathrm{CF}_{3} \mathrm{CO}_{2} \mathrm{H}$ in $\mathrm{CDCl}_{3}$ was next prepared. A methyl doublet at $\delta_{\mathrm{H}} 1.11$ and a multiplet at $\delta_{\mathrm{H}} 5.66$ revealed that protonation at $\mathrm{C}(5)$ of $\mathbf{4 a}$ had occurred to give trifluoroacetate salt $\mathbf{5 a}$, in which the neighboring relationship of the acetyl and iminium groups is revealed through a strong hydrogen bond $\left(\delta_{\mathrm{H}}\right.$ 12.45; Fig. 4$)$.

The story of the cryptic condensation product can now be wrapped up: combinations of diacetyl (1) and arylamines (2) usually precipitate diimines $\mathbf{3}$ from solutions in ethanol, but gen-
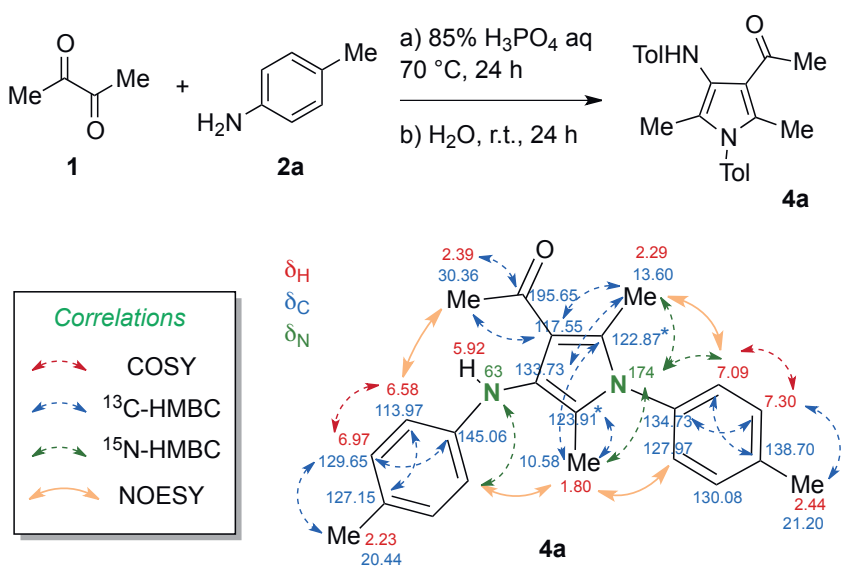

Fig. 3. Structure of $4 a$ with ${ }^{1} \mathrm{H},{ }^{13} \mathrm{C}$, and ${ }^{15} \mathrm{~N}$ chemical shifts and $2 \mathrm{D}$ NMR correlations. Starred signals are interchangeable. erate a different product in hot mineral acid, now established to be a fully substituted $\mathrm{N}$-aryl-2,5-dimethyl-3-acetyl-4-(arylamino) pyrrole (4). The structure elucidation of $\mathbf{4}$ by classical means was thwarted by a lack of recognizable fragments derived from the heterocyclic core, and by the inability of amino-substituted acylpyrroles to give Schiff base type derivatives. With hindsight, the clues from Table 1 must be partially revised: the two double bond equivalents ascribed to ring closures correspond to one pyrrole ring and one unrecognized $\mathrm{C}=\mathrm{O}$ double bond (entry 11). The finding of two $\mathrm{C}=\mathrm{C}$ double bonds by bromine titration and catalytic hydrogenation (entry 4 ) remains ambiguous in the absence of hints that such unsaturations could be part of a weakly aromatic pyrrole core. The source of the second acidic hydrogen in the Zerewitinoff test is presumably the acetyl group, which is deprotonated by the Grignard reagent rather than undergoing 1,2-addition (entry 5). Salt formation of $\mathbf{4 a}$ with $\mathrm{HCl}(g)$ is confirmed (entry 7 ), but occurs by $C$-protonation of an enamine type carbon rather than at amine nitrogen. Some information was experimentally valid, but inconclusive, since the respective analytical reactions operated outside their standard range. This is the case for the supposed nitroso derivative from secondary amine (entry 8), the photooxygenation of a $\mathrm{C}=\mathrm{C}$ double bond (entry 14), or the color reactions for heterocycles, which normally require the presence of at least one unsubstituted $\mathrm{C}-\mathrm{H}$ within the heterocycle.

The course of the reaction leading from $\mathbf{1}$ and $\mathbf{2 a}$ to $\mathbf{4 a}$ in an acidic reaction medium can be outlined as follows (Scheme 2):
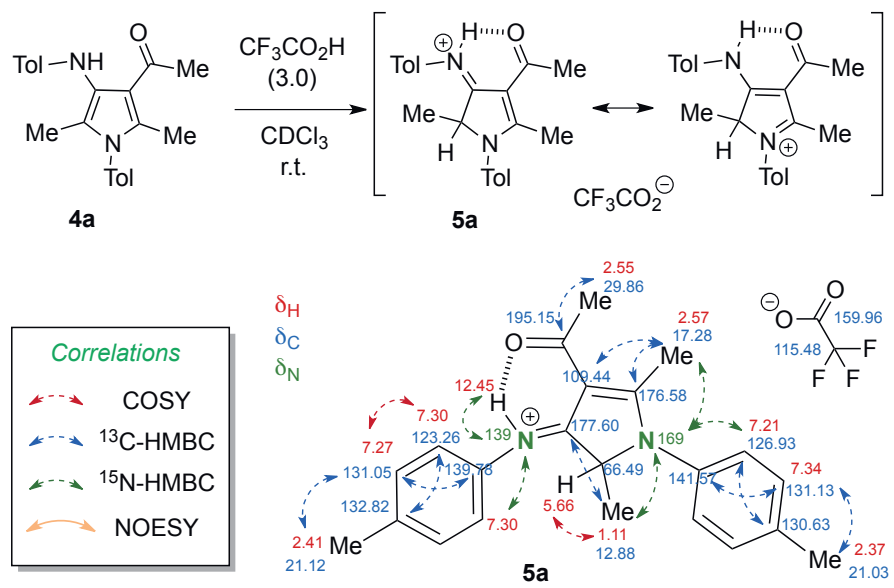

Fig. 4. Protonation of $4 a$ with trifluoroacetic acid in $\mathrm{CDCl}_{3}$, and 2D-NMR structure elucidation of the resulting salt.
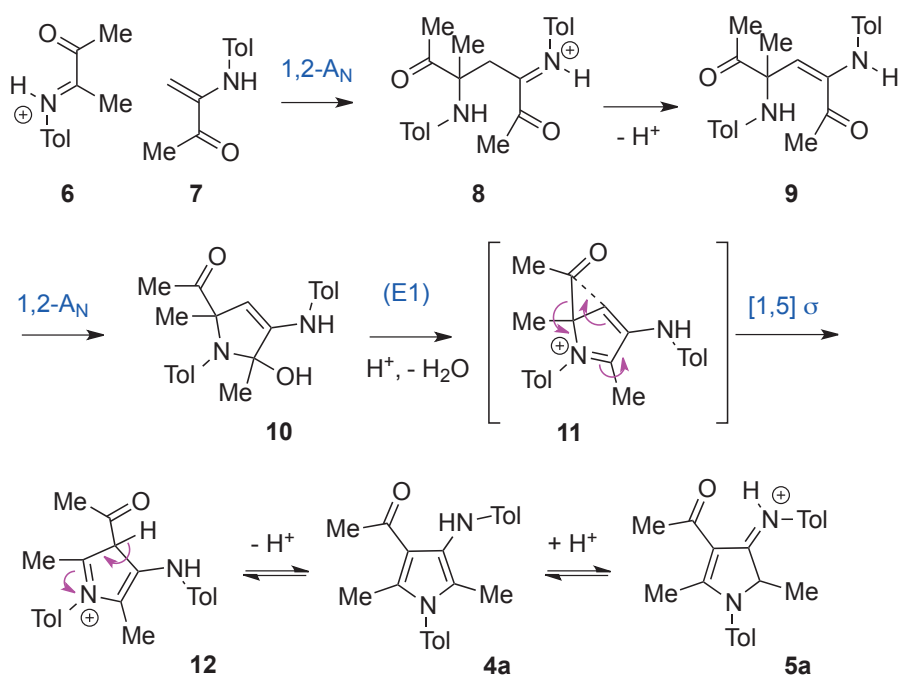

Scheme 2. Mechanistic rationale for the condensation leading to $4 \mathbf{a} / \mathbf{5 a}$. 
The 1:1 stoichiometry of $\mathbf{1}$ and $\mathbf{2}$ favors generation of protonated monoimine $\mathbf{6}$ and enamine $\mathbf{7}$, which undergo Mannich type addition to give $\mathbf{8}$. Tautomerization and intramolecular 1,2-addition provide dihydropyrrole 10, which has all groups except acetyl in the correct position. The crucial shift can be formulated as 1,5-sigmatropic rearrangement, or alternatively as Fries type rearrangement if $\mathbf{1 1}$ and $\mathbf{1 2}$ are interpreted as two $\sigma$-complexes of the same pyrrole with an acylium cation. Acid-base-equilibria interconvert $\mathbf{1 2}$ with target pyrrole $\mathbf{4 a}$ and its conjugate acid $\mathbf{5 a}$ as the most stable species under reaction conditions.

\section{Conclusion}

A fascinating aspect of organic chemistry is that combination of a few simple reactants can give rise to near unpredictable reaction products. We have chanced upon a 1949 publication that describes the condensation of diacetyl (1) and arylamines (2) in phosphoric acid to a new type of product $\mathbf{4}$, to which no structure could be assigned, in spite of the apparent simplicity of the reaction. The failure of textbook-type carbonyl derivatization reactions due to peculiarities of the target structure prevented the original authors from arriving at a satisfactory structure proposal. It turned out to be expectedly trivial to assign the structure by means of present-day 1D and 2D NMR techniques, although the final choice among several regioisomers of pyrrole $4 \mathbf{a}(\mathbf{G}$ over $\mathbf{F}$ or $\mathbf{H}$; $c f$. Scheme 2) was not trivial, and the decision relied on few NOESY cross-peaks. The in situ protonation of $\mathbf{4 a}$ by trifluoroacetic acid to give salt $\mathbf{5 a}$ tremendously simplified the 2D NMR analysis by introducing a hydrogen onto the heterocyclic core. The structural assignment of progenitor $\mathbf{4 a}$ is further secured as a consequence, which shows that reactivity considerations and derivatization reactions continue to be invaluable complements to spectroscopic techniques of structure elucidation. In the instance, the identity of a family of condensation products studied in a 1946 $\mathrm{PhD}$ thesis work ${ }^{[15]}$ and reported in a 1949 publication ${ }^{[13]}$ has been clarified, bringing closure to this curious case, and potentially opening up new synthetic opportunities.

\section{Acknowledgements}

I thank the Hans-Fischer-Gesellschaft for support of our research sometimes involving pyrroles.

\section{Supplementary Information}

Experimental information, substance characterization data, and NMR spectra are available as Supplementary Information on https:// www.ingentaconnect.com/content/scs/chimia

Received: January 18, 2020

[1] H. von Pechmann, Ber. Dtsch. Chem. Ges. 1888, 21, 1411, doi:10.1002/ cber.188802101262.

[2] H. tom Dieck, M. Svoboda, T. Greiser, Zeitschr. Naturforsch. B 1981, 36, 823, doi:10.1515/znb-1981-0709.

[3] D. Vorländer, W. Zeh, H. Enderlein, Ber. Dtsch. Chem. Ges. 1927, 60, 849, doi:10.1002/cber.19270600407.

[4] J. M. Kliegman, R. K. Barnes, J. Org. Chem. 1970, 35, 3140, doi:10.1021/ jo00834a062.

[5] G. Bühr, A. Kretzer, Zeitschr. Anorg. Allg. Chem. 1952, 267, 161, doi:10.1002/zaac.19522670116.

[6] H. Erlenmeyer, H. Lehr, Helv. Chim. Acta 1946, 29, 69, doi:10.1002/ hlca. 19460290113

[7] P. Klein, V. D. Lechner, T. Schimmel, L. Hintermann, Chem. Eur. J. 2020, 26, 176, doi:10.1002/chem.201904545.

[8] Hans Erlenmeyer (1900-1967) was a grandson of Emil Erlenemeyer senior (1825-1909), the inventor of the flask bearing his name and the first professor of chemistry at the authors' home institution (TU München).

[9] H. Bloch, H. Erlenmeyer, H. P. Furger, Helv. Chim. Acta 1944, 27, 414, doi:10.1002/hlca.19440270151.
[10] a) H. Bloch, H. Lehr, H. Erlenmeyer, Helv. Chim. Acta 1945, 28, 1406, doi:10.1002/hlca.6602801198; b) H. Bloch, G. Brubacher, H. Erlenmeyer, E. Suter, Helv. Chim. Acta 1947, 30, 539, doi:10.1002/hlca.19470300216.

[11] H. Bloch, H. Lehr, H. Erlenmeyer, K. Vogler, Helv. Chim. Acta 1945, 28, 1410, doi:10.1002/hlca.6602801199.

[12] H. Erlenmeyer, H. Lehr, H. Bloch, Helv. Chim. Acta 1945, 28, 1413, doi:10.1002/hlca.6602801200.

[13] F. Christen, B. Prijs, H. Lehr, Helv. Chim. Acta 1949, 32, 56, doi:10.1002/ hlca.19490320112.

[14] The roman numeral ' $I$ ' might indicate that a second paper was planned; in any case, no such work has appeared.

[15] F. Christen, 'Zur Kenntnis von biologisch wirksamen Kondensationsprodukten aus primären aromatischen Aminen', Dissertation, Universität Basel, 1946, http://permalink.snl.ch/bib/sz000580094.

[16] Fritz Christen (1911-1987), born in Basel; studies of chemistry at Universität Basel; worked as analytical chemist at CIBA/Ciba-Geigy until 1978.

[17] R. W. Hoffmann, 'Classical Methods in Structure Elucidation of Natural Products', Wiley-VHCA, 2018, doi:10.1002/9783906390819

[18] In an obvious printing error, ref. [13] writes this as: $2 \mathrm{R}-\mathrm{C}_{6} \mathrm{H}-\mathrm{NH}_{2}+$ $\mathrm{CH}_{3} \mathrm{COCOCH}_{3}=\mathrm{C}_{20} \mathrm{H}_{18} \mathrm{ON}_{2} \mathrm{R}_{2}+\mathrm{H}_{2} \mathrm{O}$

[19] Calculated from the molecular formula: M. Hesse, H. Meier, B. Zeeh, 'Spektroskopische Methoden in der organischen Chemie', 8th Edn., Georg Thieme Verlag, 2005, doi:10.1055/b-002-46985

[20] T. Zerewitinoff, Ber. Dtsch. Chem. Ges. 1907, 40, 2023, doi:10.1002/ cber. 190704002115

[21] The $N$-acetyl derivative of 4 a was also re-synthesized. See the Supplementary Information for additional information.

[22] A spruce chip or shaving of pine wood, moistened with hydrochloric acid, develops a color when exposure to certain electron-rich, (hetero)aromatic compounds. Runge introduced this highly sensitive color test for the then newly discovered compounds aniline (yellow) and pyrrol (deep red) from coal tar: F. F. Runge, Ann. Physik Chem. 1834, 107, 65, doi:10.1002/ andp. 18341070502 .

[23] The Carr-Price reagent, $\mathrm{SbCl}-\mathrm{Ac}_{2} \mathrm{O}-\mathrm{CHCl}$, develops color with vitamin $\mathrm{A}$, but also with other polyenes or furans: F. H. Carr, E. A. Price, Biochem. J. 1926, 20, 497, doi: 10.1042/bj0200497.

[24] A. Wettstein, K. Miescher, Helv. Chim. Acta 1943, 26, 788, doi:10.1002/ hlca. 19430260312.

[25] Melting points are valuable to confirm the identity of products obtained from historical synthetic procedures. The small discrepancy in the case of 4a may be due to the use of corrected temperature in ref. [13], which can introduce deviations. Recent measurements using digital thermometers are inherently corrected, compare: G. V. D. Tiers, J. Chem. Educ. 1990, 67, 258, doi:10.1021/ed067p258.

[26] M. Findeisen, S. Berger, '50 and More Essential NMR Experiments, A Detailed Guide', Wiley-VCH, Weinheim, 2014, ISBN: 978-3-527-33483-4.

[27] a) T. F. Molinski, B. I. Morinaka, Tetrahedron 2012, 68, 9307, doi:10.1016/j. tet.2011.12.070; b) K. N. White, T. Amagata, A. G. Oliver, K. Tenney, P. J. Wenzel, P. Crews, J. Org. Chem. 2008, 73, 8719, doi:10.1021/jo800960w; c) G. E. Martin, A. J. Williams, D. Rovnyak, in 'Modern NMR Approaches to the Structure Elucidation of Natural Products, Vol. 1', Eds. A. Williams, G. Martin, D. Rovnyak, The Royal Society of Chemistry, Cambridge, 2016, Chapter 1, doi:10.1039/9781849735186-00001.

[28] For an extreme case from our research, see bis-oxyluciferin $\left(\mathrm{C}_{20} \mathrm{H}_{12} \mathrm{~N}_{4} \mathrm{O}_{4} \mathrm{~S}_{4}\right.$; $\mathrm{H} / \mathrm{X}$ ratio 0.375 ), whose structure was assigned without recording $2 \mathrm{D} \mathrm{NMR}$ data, but using ${ }^{13} \mathrm{C}$ - and ${ }^{15} \mathrm{~N}$-labeling techniques: O. V. Maltsev, N. K. Nath, P. Naumov, L. Hintermann, Angew. Chem. Int. Ed. 2014, 53, 847, doi:10.1002/ anie. 201307972.

[29] The superscript corresponds to $\delta_{\mathrm{H}}$ of the respective methyl or tolyl (ortho$\mathrm{CH})$ group.

[30] The correlation between ${ }^{2.39} \mathrm{MeCO}$ to ${ }^{2.29} \mathrm{Me}$ was hidden by center-line noise.

[31] T. B. Toube, in 'Chemistry of Heterocyclic Compounds: Pyrroles, Part 2', Ed. R. A. Jones, John Wiley \& Sons, 1992; p. 12, doi:10.1002/9780470187340. ch1.

[32] R. A. Jones, G. P. Bean, The Chemistry of Pyrroles, Academic Press, 1977, doi:10.1016/c2013-0-07399-9.

\section{License and Terms}

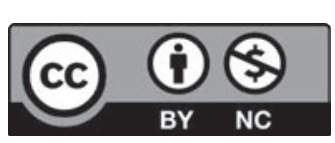

This is an Open Access article under the terms of the Creative Commons Attribution License CC BY_NC 4.0. The material may not be used for commercial purposes.

The license is subject to the CHIMIA terms and conditions: (http:// chimia.ch/component/sppagebuilder/?view=page \&id=12).

The definitive version of this article is the electronic one that can be found at doi:10.2533/chimia.2020.293 